\title{
Identification and Quantification of Ascospores as the Primary Inoculum for Collar Rot of Greenhouse-Produced Tobacco Seedlings
}

\author{
W. A. Gutierrez and H. D. Shew, Department of Plant Pathology, Box 7616, North Carolina State University, Ral- \\ eigh 27695
}

\begin{abstract}
Gutierrez, W. A., and Shew, H. D. 1998. Identification and quantification of ascospores as the primary inoculum for collar rot of greenhouse-produced tobacco seedlings. Plant Dis. 82:485490.

Collar rot, caused by Sclerotinia sclerotiorum, is a severe disease of tobacco seedlings grown in greenhouses. A semiselective medium was adapted and used to detect the presence and quantity of ascospores in commercial greenhouses. Petri dishes of the semiselective medium were placed inside and outside of greenhouses in four counties during the transplant production period in 1995 and 1996. Ascospores were present throughout the production period each year (February to April) and were confirmed to be the primary inoculum for the disease. Significant differences were observed in the number of ascospores trapped within and between counties. Peak numbers of ascospores were trapped between 10 and 12 A.M., and higher numbers of ascospores were trapped outside than inside houses. In general, distribution of ascospores inside houses was uniform unless a high concentration of apothecia was present very close to one section of the greenhouse. The semiselective medium and trapping technique used in this study may allow development of a forecasting system for collar rot of tobacco based on the presence and level of pathogen inoculum.
\end{abstract}

Additional keywords: Nicotiana tabacum, spore trapping

Production of tobacco transplants has changed in recent years from the use of open beds and overhead irrigation in the field to the use of float tray systems under greenhouse conditions. This change in production system has resulted in new disease problems that rarely were observed under field conditions. One of the most potentially devastating of these diseases is collar rot, caused by Sclerotinia sclerotiorum. Incidence of this disease has increased as the percentage of transplants produced under greenhouse conditions has increased.

The primary inoculum for most diseases caused by $S$. sclerotiorum is ascospores $(2,7,10,16,18)$. These spores are released from apothecia that are produced from sclerotia that overwinter or oversummer in the soil. Ascospores are wind disseminated, and although dissemination of up to $2 \mathrm{~km}$ has been reported, most spores are thought to travel less than $100 \mathrm{~m}$ from their source (2). This steep dispersal gradient increases the possibility of finding and eliminating sources of primary inoculum of the pathogen.

Corresponding author: H. D. Shew

E-mail: d_shew@ncsu.edu

Accepted for publication 17 January 1998.

Publication no. D-1998-0310-02R

(C) 1998 The American Phytopathological Society
The production of tobacco transplants in side-vent greenhouses begins in early spring (February) in North Carolina. Sterilized polystyrene trays are filled with a soilless medium and then seeded with pelletized tobacco seed. Trays are then floated on a water reservoir that contains necessary nutrients for growth. Seedlings are kept in the greenhouse for several months, until environmental conditions are favorable for transplanting. During this period, growers open greenhouse vents (side walls) when weather conditions allow in order to increase aeration and reduce humidity in the house.

Collar rot usually is observed only during the second half of the production period, after a canopy has formed among seedlings. Symptoms of collar rot typically are observed in foci (10 to $40 \mathrm{~cm}$ in diameter) in different areas in the greenhouse and are first noticed as a wilting of affected plants. Subsequent symptoms and signs include production of a water-soaked lesion and cottony mycelium on infected tissues. Objectives of this study were to identify and quantify the primary inoculum of S. sclerotiorum in tobacco greenhouses in North Carolina and to determine the spatial and temporal distribution of the inoculum in greenhouses during the tobacco transplant production period.

\section{MATERIALS AND METHODS}

Sampling sites. Experiments were conducted in four tobacco-producing counties in central and eastern North Carolina during 1995 and 1996. In 1995, three commercial tobacco greenhouses were selected about halfway through the production period. One greenhouse was in Lenoir County (Sm), and two were in Jones County (Wa-2 and Jo-1). Collar rot had been observed in all three greenhouses prior to sampling. In 1996, 11 commercial greenhouses were selected for trapping, one in Lenoir (S), four in Jones (Wa-1, Wa-2, Jo-1, and Jo-2), three in Martin (Ma1, Ja-1, and $\mathrm{Ja}-2$ ), and three in Caswell (Th, Ya, and $\mathrm{Ri}$ ) counties; greenhouse float beds ranged from 80 to $180 \mathrm{~m}^{2}$. Collar rot was observed in all 11 houses in 1995 , but sampling began prior to disease development in 1996.

Trapping of ascospores. A semiselective medium was used for trapping $S$. sclerotiorum ascospores. The medium was based on the media described by Williams and Stelfolk (18), Ben-Yephet and Bitton (2), and Godoy et al. (5), and is a modification of the medium reported by Steadman et al. (14). The medium contains $3 \%$ (30 g/liter) potato dextrose agar (PDA), streptomycin sulfate $(100 \mu \mathrm{g} / \mathrm{liter})$, penicillin-G sodium salt $(100 \mu \mathrm{g} /$ liter $)$, calcium chloride (50 mg/liter), bromophenol blue (50 mg/liter), PCNB (15 mg a.i./liter), and etridiazole (35 mg a.i./liter). Antibiotics and fungicides were added to the medium after sterilization $\left(121^{\circ} \mathrm{C}\right.$ for $\left.30 \mathrm{~min}\right)$.

Petri dishes ( $9 \mathrm{~cm}$ diameter) of the semiselective medium were placed inside and outside of greenhouses in a predetermined design (Fig. 1). In 1995, intensive sampling was done inside greenhouses to determine the distribution of ascospores. Greenhouses were divided into two sides (left and right); each side was subdivided into three areas (close to the central walkway, middle of the seedling bed, and close to the wall); and the whole greenhouse was divided into three sections, entrance, middle, and back (Fig. 1). For each section, 12 dishes of the semiselective medium were placed 1 to $2.5 \mathrm{~m}$ apart (72 dishes per greenhouse) directly on the top of the seedling canopy. Outside, dishes were placed on the ground around the greenhouse at 1 and $5 \mathrm{~m}$ from the wall. In 1996, the overall pattern of placement was similar, but fewer dishes were used (Fig. 1).

To trap ascospores, lids were removed and the dishes were left open for $1 \mathrm{~h}$. All trapping was conducted between 9 and 11 
A.M. (2), once or twice weekly throughout the tobacco transplant production period (February through early April). After exposure for $1 \mathrm{~h}$, lids were replaced, and dishes were collected and incubated in the dark at 21 to $23^{\circ} \mathrm{C}$. After 3 days of incubation, colonies of $S$. sclerotiorum were counted. A colony was considered to be originated by one ascospore growing on the semiselective medium. To determine the time of the day that ascospores were present in highest numbers, hourly trapping was conduced from 6 A.M. to 3 P.M. inside and outside of greenhouse Wa-2 in 1995 and 1996. The test was conducted on three sampling dates in 1995 and on 1 day in 1996.

Disease evaluation. Between 60 and 100 trays were examined in each greenhouse to determine the incidence of collar rot. Trays along the central walkway were examined weekly for the presence of cottony mycelium and water-soaked lesions characteristic of collar rot. Isolation from symptomatic tissues onto either the semiselective me- dium or PDA was used to confirm the presence of S. sclerotiorum.

Data analyses. Data were averaged for each sampling date at each location, and distribution of the inoculum inside and outside greenhouses was analyzed by the PROC GLM procedures of SAS (SAS Institute, Cary, NC). Means were separated by Duncan's multiple range test and by Fisher's protected least significant differences (LSD) test. In addition, chi-square goodness of fit tests were used to determine if the distribution of ascospores inside greenhouses was random (fit a Poisson distribution) $(12,13,15)$ by analyzing each sampling date in the Jo-2, Sm, and Wa-2 greenhouses in Jones and Lenoir counties in 1995.

\section{RESULTS}

Colonies of $S$. sclerotiorum on the semiselective medium had a characteristic morphology (small round colony with a raised mycelial mass in the center of the colony) and a yellow halo. The yellow halo
Table 1. Average number of Sclerotinia sclerotiorum ascospores trapped during 1995 to 1996 in tobacco greenhouses

\begin{tabular}{lcc}
\hline $\begin{array}{l}\text { Location/ } \\
\text { grower }\end{array}$ & $\mathbf{1 9 9 5}$ & $\mathbf{1 9 9 6}$ \\
\hline Lenoir S & $2.41^{\mathrm{y}} \mathrm{b}^{\mathrm{z}}$ & $2.06^{\mathrm{y}} \mathrm{c}^{\mathrm{z}}$ \\
Jones W-1 & $\ldots$ & $7.31 \mathrm{~b}$ \\
Jones W-2 & $43.89 \mathrm{a}$ & $13.65 \mathrm{a}$ \\
Jones J-1 & $0.38 \mathrm{c}$ & $0.20 \mathrm{c}$ \\
Jones J-2 & $\ldots$ & $0.31 \mathrm{c}$ \\
Caswell T & $\ldots$ & $0.25 \mathrm{a}$ \\
Caswell R & $\ldots$ & $0.08 \mathrm{~b}$ \\
Caswell Y & $\ldots$ & $0.03 \mathrm{c}$ \\
Martin Gh & $\ldots$ & $0.47 \mathrm{~b}$ \\
Martin J-1 & $\ldots$ & $0.51 \mathrm{~b}$ \\
Martin J-2 & $\ldots$ & $0.66 \mathrm{a}$ \\
\hline
\end{tabular}

y Average number of $S$. sclerotiorum ascospores trapped per-9-cm diameter petri dish of semiselective medium during a 1-h exposure inside and outside greenhouses.

${ }^{\mathrm{z}}$ Different letters indicate significant differences $(P=0.05)$ according to Duncan's multiple range test.
1995

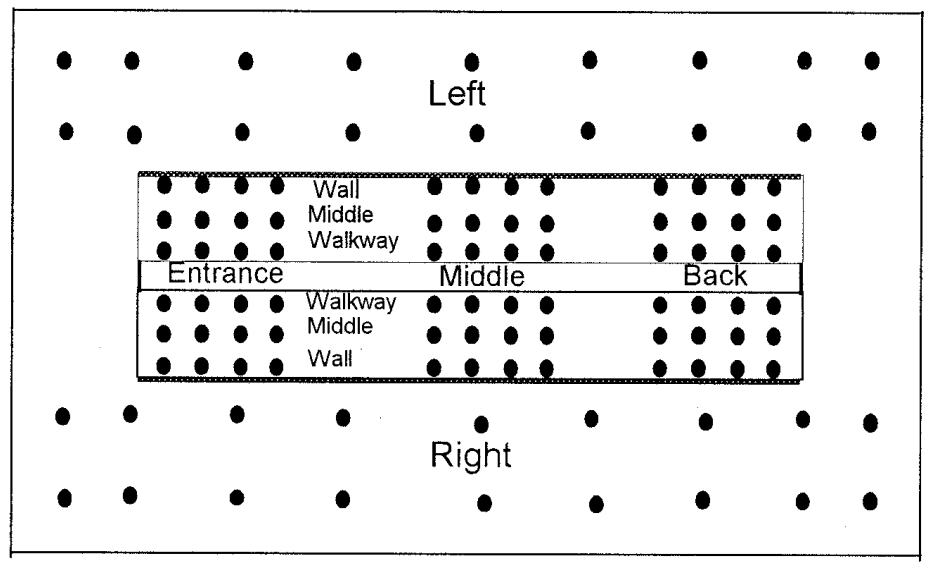

1996

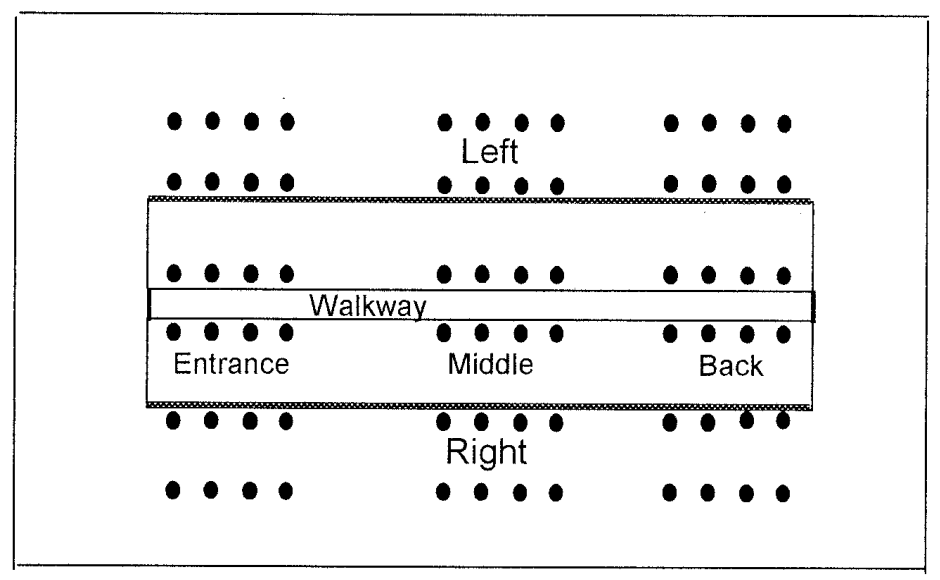

Fig. 1. Diagram of plate distribution inside and outside greenhouses during 1995 and 1996. Location of petri dish of semiselective medium (dark circles).
A

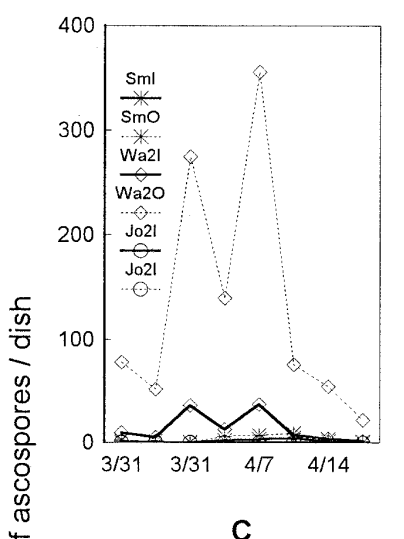

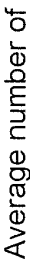

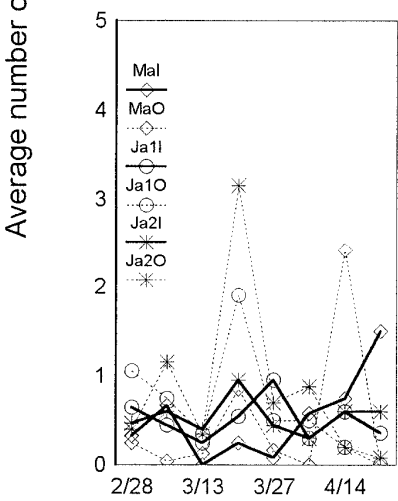

Date

Fig. 2. Average number of Sclerotinia sclerotiorum ascospores trapped on each 9-cm-diameter petri dish in tobacco greenhouses during 1995 and 1996 in different counties, (A) Jones and Lenoir county area (1995), (B) Jones and Lenoir county area (1996), (C) Martin County, and (D) Caswell County. Capital letters (Sm, Wa, Jo, Ma, Ja, Th, Ya, and $\mathrm{Ri}$ ) correspond to grower location. Number $(1,2$, or none) corresponds to number of greenhouses sampled for a given grower, if more than 1 . Letter $\mathrm{I}=$ inside greenhouse, and $\mathrm{o}=$ outside greenhouse. Solid line corresponds to ascospore numbers inside greenhouse, and dotted line corresponds to ascospore numbers outside greenhouse. 
that formed after 2 to 3 days was the result of a change in $\mathrm{pH}$ of the medium and was attributed to the production oxalic acid produced by $S$. sclerotiorum (14).

Ascospores of $S$. sclerotiorum were present throughout the transplant production period in both 1995 and 1996. Ascospore numbers varied with location, over time at a given location, and by year (Fig. 2A to D). The variation in ascospore numbers over time at the same location indicated a cyclic release of inoculum in the field (Fig. $2 \mathrm{~A}$ to $\mathrm{D})$. This variation was most apparent in locations with high levels of inoculum, such as in greenhouse Wa-2 in Jones County (Fig. 2A and B). When inoculum concentrations were low (average of less than one colony per dish), as in the greenhouses in Caswell and Martin counties, variation over time was not as noticeable (Fig. 2C and D).

The average number of colonies of $S$. sclerotiorum trapped per dish in a 1-h exposure ranged from $<1$ to 44 in 1995 and from <1 to 14 in 1996 (Table 1). The greenhouses in Jones County had the highest levels of inoculum, and greenhouse Wa-2 had the highest level of all greenhouses, with an average of 44 colonies per petri dish. This number of ascospores per dish equated to a mean deposition of about 6,900 ascospores per $\mathrm{m}^{2}$ of seedling tray per $\mathrm{h}\left(\mathrm{m}^{2} / \mathrm{h}\right)$. The lowest mean counts were in greenhouse Jo-1, with an average of less than one colony per dish or 62 ascospores per $\mathrm{m}^{2} / \mathrm{h}$. Other greenhouses in Martin, Caswell, and Jones counties had intermediate inoculum levels (Table 1).

Ascospore numbers were generally higher outside than inside greenhouses. This was especially true of greenhouses in Jones and Lenoir counties (Table 2). In Martin County, the number of ascospores trapped outside was higher than inside, but the difference was not significant. A similar trend was found in greenhouses in

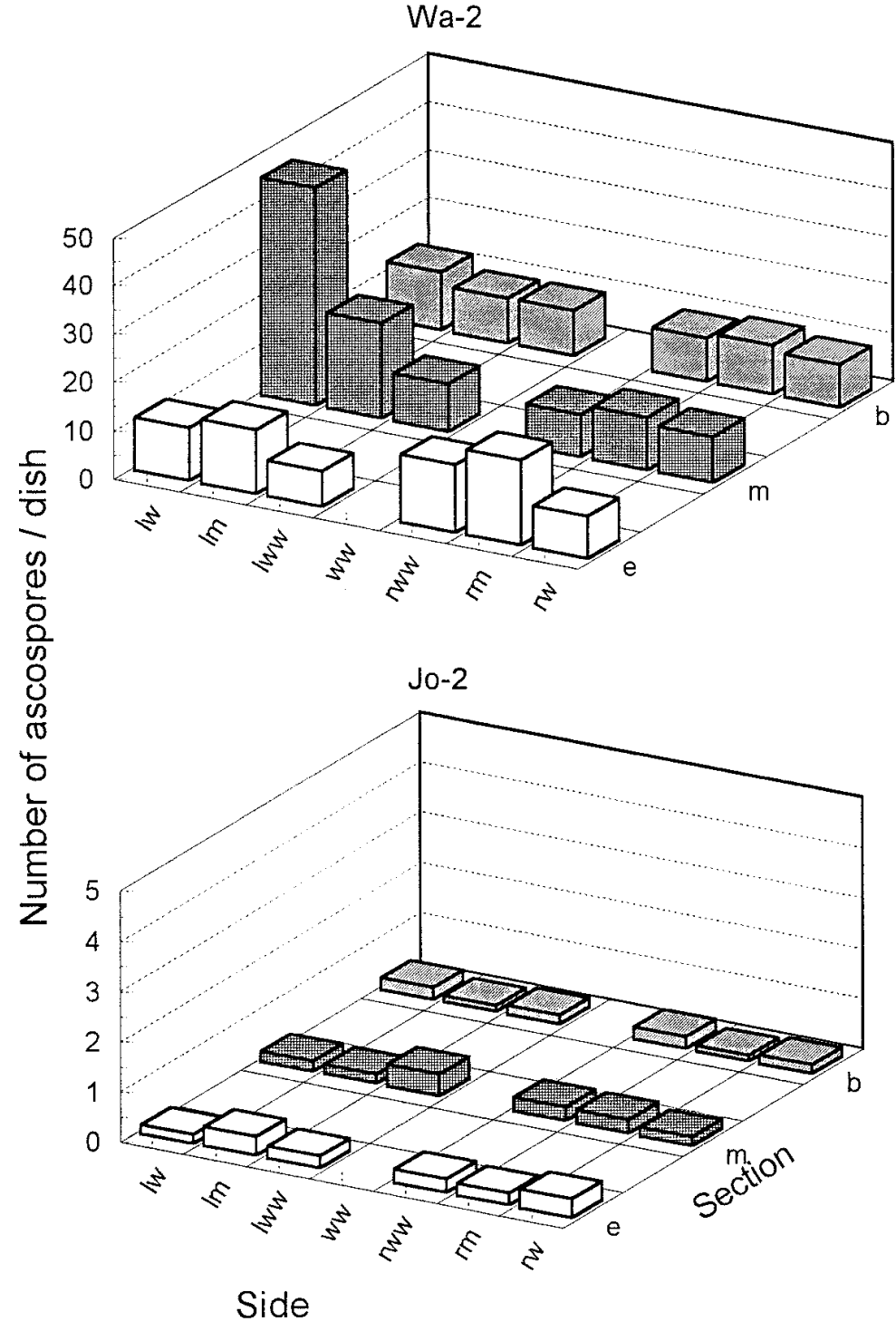

Fig. 3. Diagram of the distribution of ascospores trapped inside greenhouses in Jones and Lenoir county area during 1995. Letters indicate different sections into which the greenhouse was divided. L $=$ left, $\mathrm{R}=$ right, $\mathrm{ww}=$ walkway, $\mathrm{m}=$ middle, $\mathrm{w}=$ wall, $\mathrm{e}=$ entrance, and $\mathrm{b}=$ back. Average number of ascospores trapped per 9-cm-diameter petri dish.

Table 2. Average number of ascospores trapped on a semiselective medium in 1-h exposures in different sections of a tobacco greenhouse sampled during 1995 and 1996

\begin{tabular}{|c|c|c|c|c|c|c|c|c|c|c|c|}
\hline \multirow[b]{3}{*}{ Location } & \multirow{2}{*}{\multicolumn{3}{|c|}{$\begin{array}{c}1995 \\
\text { Lenoir-Jones }\end{array}$}} & \multicolumn{8}{|c|}{1996} \\
\hline & & & & \multicolumn{2}{|c|}{ Lenoir-Jones } & \multicolumn{3}{|c|}{ Martin } & \multicolumn{3}{|c|}{ Caswell } \\
\hline & $\mathbf{S}$ & W2 & $\mathbf{J 2}$ & S1 & W2 & $\mathrm{J} 2$ & Gh & $\mathbf{J 2}$ & $\mathbf{T}$ & $\mathbf{R}$ & $\mathbf{Y}$ \\
\hline \multicolumn{12}{|c|}{ Greenhouse } \\
\hline Inside & $1.81^{\mathrm{y}} \mathrm{b}^{\mathrm{z}}$ & $14.56 \mathrm{~b}$ & $0.25 \mathrm{~b}$ & $0.51 \mathrm{~b}$ & $4.93 \mathrm{~b}$ & $0.13 \mathrm{~b}$ & $0.53 \mathrm{a}$ & $0.56 \mathrm{a}$ & $1.02 \mathrm{a}$ & $0.12 \mathrm{a}$ & $0.04 \mathrm{a}$ \\
\hline Outside & $4.21 \mathrm{a}$ & $131.86 \mathrm{a}$ & $0.75 \mathrm{a}$ & $2.47 \mathrm{a}$ & $15.82 \mathrm{a}$ & $0.36 \mathrm{a}$ & $0.28 . a$ & $0.65 \mathrm{a}$ & $0.06 \mathrm{~b}$ & $0.08 \mathrm{a}$ & $0.03 \mathrm{a}$ \\
\hline \multicolumn{12}{|l|}{ Section } \\
\hline Entrance & $2.62 \mathrm{a}$ & $42.40 \mathrm{~b}$ & $0.48 \mathrm{a}$ & $1.52 \mathrm{~b}$ & $20.35 \mathrm{a}$ & $0.31 \mathrm{a}$ & $0.45 \mathrm{a}$ & $0.68 \mathrm{a}$ & $0.31 \mathrm{a}$ & $0.06 \mathrm{a}$ & $0.03 \mathrm{a}$ \\
\hline Middle & $2.15 \mathrm{~b}$ & $61.74 \mathrm{a}$ & $0.35 \mathrm{~b}$ & $1.70 \mathrm{~b}$ & $11.09 \mathrm{ab}$ & $0.32 \mathrm{a}$ & $0.17 \mathrm{a}$ & $0.64 \mathrm{a}$ & $0.26 \mathrm{a}$ & $0.06 \mathrm{a}$ & $0.05 \mathrm{a}$ \\
\hline Back & $2.46 \mathrm{ab}$ & $27.53 \mathrm{c}$ & $0.30 \mathrm{~b}$ & $3.12 \mathrm{a}$ & $8.38 \mathrm{~b}$ & $0.31 \mathrm{a}$ & $0.36 \mathrm{a}$ & $0.67 \mathrm{a}$ & $0.19 \mathrm{a}$ & $0.09 \mathrm{a}$ & $0.03 \mathrm{a}$ \\
\hline \multicolumn{12}{|l|}{ Side } \\
\hline Left & $2.26 \mathrm{a}$ & $55.44 \mathrm{a}$ & $0.38 \mathrm{a}$ & $1.76 \mathrm{a}$ & $29.30 \mathrm{a}$ & $0.35 \mathrm{a}$ & $0.35 \mathrm{a}$ & $0.69 \mathrm{a}$ & $0.04 \mathrm{a}$ & $0.09 \mathrm{a}$ & $0.05 \mathrm{a}$ \\
\hline Right & $2.55 \mathrm{a}$ & $32.33 \mathrm{~b}$ & $0.37 \mathrm{a}$ & $3.10 . \mathrm{a}$ & $5.04 \mathrm{~b}$ & $0.36 \mathrm{a}$ & $0.20 \mathrm{a}$ & $0.67 \mathrm{a}$ & $0.08 \mathrm{a}$ & $0.06 \mathrm{a}$ & $0.01 \mathrm{a}$ \\
\hline \multicolumn{12}{|l|}{ Distance } \\
\hline $0 \mathrm{~m}$ & $1.81 \mathrm{c}$ & $14.56 \mathrm{~b}$ & $0.26 \mathrm{~b}$ & $0.51 \mathrm{~b}$ & $4.93 \mathrm{~b}$ & $0.13 \mathrm{~b}$ & $0.53 \mathrm{a}$ & $0.57 \mathrm{~b}$ & $1.02 \mathrm{a}$ & $0.12 \mathrm{a}$ & $0.42 \mathrm{a}$ \\
\hline $1 \mathrm{~m}$ & $4.51 \mathrm{a}$ & $253.08 \mathrm{a}$ & $0.79 \mathrm{a}$ & $3.86 \mathrm{a}$ & 28.89 a & $0.36 \mathrm{a}$ & $0.44 \mathrm{a}$ & $0.88 \mathrm{a}$ & $0.07 \mathrm{~b}$ & $0.10 \mathrm{a}$ & $0.25 \mathrm{a}$ \\
\hline $5 \mathrm{~m}$ & $3.91 \mathrm{~b}$ & $10.69 \mathrm{~b}$ & $0.71 \mathrm{a}$ & $0.87 \mathrm{~b}$ & $0.88 \mathrm{~b}$ & $0.35 \mathrm{a}$ & $0.18 \mathrm{~b}$ & $0.49 \mathrm{~b}$ & $0.04 \mathrm{~b}$ & $0.05 \mathrm{a}$ & $0.33 \mathrm{a}$ \\
\hline
\end{tabular}

${ }^{\mathrm{y}}$ Average number of Sclerotinia sclerotiorum ascospores trapped on a 9-cm-diameter petri dish of a semiselective medium during a 1-h period.

${ }^{\mathrm{z}}$ Different letters indicate significant differences $(P=0.05)$ in LSD test. 
Table 3. Test of goodness of fit to a Poisson distribution for numbers of ascospores for each sampling date inside greenhouses in Jones and Lenoir counties during 1995

\begin{tabular}{|c|c|c|c|c|c|c|}
\hline Greenhouse & Date $^{v}$ & Classes $^{w}$ & df & $\Sigma(\mathbf{O}-\mathbf{E})^{2} / \mathbf{E}^{\mathbf{x}}$ & $\chi^{2 y}$ & Significance $^{\mathrm{z}}$ \\
\hline \multirow[t]{8}{*}{ Jo-2-95 } & f1 & 4 & 2 & 4.00 & 5.99 & $\mathrm{f}$ \\
\hline & $\mathrm{f} 2$ & 4 & 2 & 2.34 & 5.99 & $\mathrm{f}$ \\
\hline & f3 & 4 & 2 & 4.08 & 5.99 & $\mathrm{f}$ \\
\hline & $\mathrm{f} 4$ & 4 & 2 & 3.31 & 5.99 & $\mathrm{f}$ \\
\hline & f5 & 4 & 2 & 0.16 & 5.99 & $\mathrm{f}$ \\
\hline & f6 & 4 & 2 & 0.63 & 5.99 & $\mathrm{f}$ \\
\hline & f7 & 3 & 1 & 0.06 & 3.84 & $\mathrm{f}$ \\
\hline & f8 & 2 & 1 & 0.01 & 3.84 & $\mathrm{f}$ \\
\hline \multirow[t]{7}{*}{ Sm-95 } & f1 & 5 & 3 & 4.87 & 7.81 & $\mathrm{f}$ \\
\hline & $\mathrm{f} 2$ & 5 & 3 & 1.37 & 7.81 & $\mathrm{f}$ \\
\hline & $\mathrm{f} 3$ & 3 & 1 & 0.64 & 3.84 & f \\
\hline & f4 & 9 & 7 & 190.81 & 14.07 & $\mathrm{nf}$ \\
\hline & f5 & 10 & 8 & 63.70 & 15.51 & $\mathrm{nf}$ \\
\hline & f6 & 7 & 5 & 94.48 & 11.01 & $\mathrm{nf}$ \\
\hline & f7 & 3 & 1 & 2.75 & 3.84 & $\mathrm{f}$ \\
\hline \multirow[t]{8}{*}{ Wa-2-95 } & $\mathrm{f} 1$ & 17 & 15 & 199.26 & 25.00 & $\mathrm{nf}$ \\
\hline & $\mathrm{f} 2$ & 11 & 9 & 16.50 & 16.92 & $\mathrm{nf}$ \\
\hline & $\mathrm{f} 3$ & 47 & 45 & $1,694.13$ & 67.50 & $\mathrm{nf}$ \\
\hline & $\mathrm{f} 4$ & 27 & 25 & $1,664.42$ & 37.65 & $\mathrm{nf}$ \\
\hline & f5 & 51 & 49 & 70.73 & 67.50 & $\mathrm{nf}$ \\
\hline & f6 & 18 & 16 & $2,441.52$ & 26.30 & $\mathrm{nf}$ \\
\hline & $\mathrm{f} 7$ & 10 & 8 & 48.02 & 15.51 & $\mathrm{nf}$ \\
\hline & f8 & 8 & 6 & 37.99 & 12.60 & $\mathrm{nf}$ \\
\hline
\end{tabular}

v Date samples were taken.

w Number of classes corresponding to the number of ascospores trapped per dish $(0,1,2,3,4, \ldots \mathrm{n}$ ascospores).

x $\chi^{2}$ value computed by summing all values obtained for individual classes.

y $\chi^{2}$ value obtained with $\mathrm{n}-2 \mathrm{df}(\mathrm{n}=$ number of classes per sampling date).

z Significance of Poisson fitness, $\mathrm{f}=$ fit, $\mathrm{nf}=$ does not fit Poisson distribution.

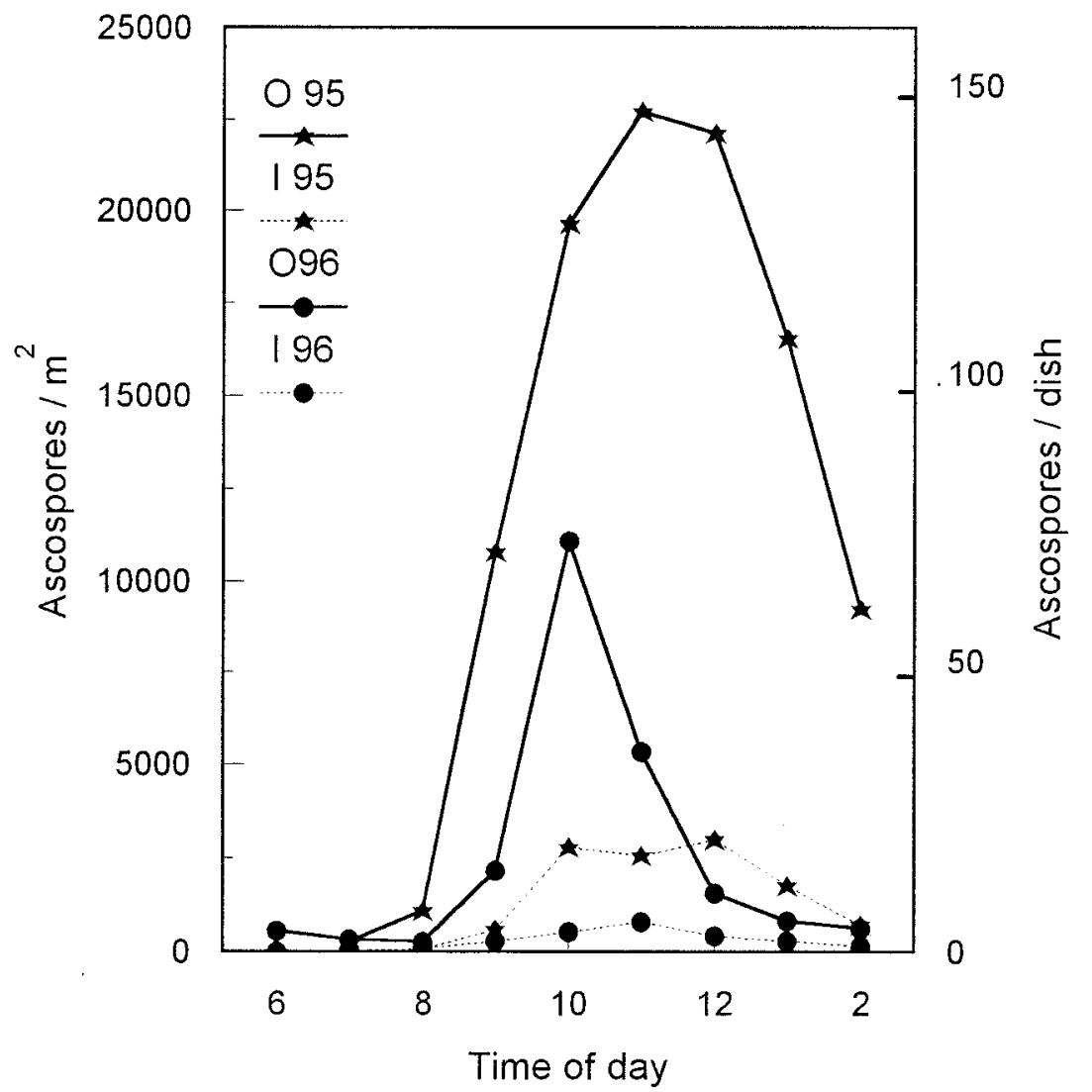

Fig. 4. Hourly distribution of Sclerotinia sclerotiorum ascospores deposited onto a tobacco seedling canopy for a 24-h period, based on the average number of ascospores trapped per 9-cm-diameter petri dish in greenhouse Wa- 2 in Jones and Lenoir county area. $\mathrm{O}=$ outside the greenhouse, $\mathrm{I}=\mathrm{in}$ side the greenhouse. Ascospores per $\mathrm{m}^{2}$ was extrapolated from ascospore numbers deposited on the area of the 9 -cm-diameter dish to the area of seedling beds.
Caswell County, except in greenhouse Th, which had a significantly higher number of spores inside than outside the greenhouse (Table 2). In addition, with only one exception, there were no significant differences in the levels of inoculum trapped in the various sections delineated within a greenhouse (Fig. 3). The one exception was in greenhouse Wa-2 in Jones County, where a very high level of inoculum was detected in the left-middle section of the greenhouse (Fig. 3, Table 2), which corresponded with the occurrence of over 100 apothecia just outside the greenhouse wall.

Chi-square goodness of fit tests for each sampling date indicated that the variation in the distribution of ascospores observed could be attributed to chance (fit Poisson distribution) for each of the sampling dates in the Jo-2 greenhouse (Table 3). In greenhouse Sm, counts from four of the sampling dates (f1, f2, f3, and f7) fit a Poisson distribution, and counts from three dates (f4, f5, and f6) did not. In greenhouse Wa2 , none of the sampling dates fit a Poisson distribution, which indicated a nonuniform distribution of ascospores inside the greenhouse (Table 3).

Outside of greenhouses, higher numbers of ascospores were trapped on dishes $1 \mathrm{~m}$ from the greenhouse wall than on dishes placed $5 \mathrm{~m}$ from the greenhouse wall. This trend was most noticeable in greenhouses Wa-2, Wa-1, and Sm from Jones and Lenoir counties in both 1995 and 1996 (Table 2).

Peak ascospore numbers occurred in late morning hours. Similar trends were observed on all days when hourly trapping was completed, with highest levels of inoculum present between 10 A.M. and noon (Fig. 4). Similar patterns were observed inside and outside the greenhouse in 1995 and 1996, with about a 1-h delay in peak ascospore numbers trapped inside compared with outside the greenhouse (Fig. 4). Overall, peak numbers were much lower inside than outside greenhouses. For example, numbers of ascospores trapped ranged from 1,000 to 23,000 ascospores per $\mathrm{m}^{2} / \mathrm{h}$ outside greenhouses to 500 to 3,000 ascospores per $\mathrm{m}^{2} / \mathrm{h}$ inside greenhouses (Fig. 4).

Collar rot was observed in all greenhouses in which inoculum levels were higher than 0.5 colonies per dish per $h$. The highest incidence of collar rot was observed in greenhouse Wa-2 in Jones County, with up to $85 \%$ of trays containing foci of collar rot (Fig. 5A and B). Incidence ranged from 10 to $20 \%$ in Martin County (Fig. 5C), and no collar rot was detected in Caswell County (Fig. 5D).

\section{DISCUSSION}

The semiselective medium used in this study facilitated the detection and quantification of $S$. sclerotiorum ascospores present in and around tobacco greenhouses. Three-day-old colonies of $S$. sclerotiorum were well defined, with a characteristic 
hyphal morphology (2) that readily allowed differentiation from other fungi. Sclerotia of S. sclerotiorum were observed on many colonies after 8 days of incubation, compared with $>10$ days previously reported (2).

The yellow haloes that formed around colonies of $S$. sclerotiorum were visible after 3 days of incubation (14). The haloes varied considerably in diameter, but only rarely were not formed at all. A few fungi other than $S$. sclerotiorum also produced haloes, but they were easily separated from S. sclerotiorum by colony morphology or the time required for the halo to form. Species of Botrytis produced haloes, but they generally required longer than 3 days to become visible. Penicillium spp. produced haloes, but the colonies were very small and readily distinguished from $S$. sclerotiorum. In addition to its ease of use in ascospore quantification, the semiselective medium is relatively inexpensive, easy to prepare, and can be used by growers or county agents to scout greenhouses for $S$. sclerotiorum.

Other studies have evaluated the presence of ascospore inoculum under field conditions $(2,14,18)$. In general, previously developed media were used to confirm the presence of ascospores (18) or to determine ascospore numbers over short periods of time $(2,14)$. The medium developed in this study was used to quantify ascospore numbers over an entire transplant production period and provided data to confirm that ascospores are the primary inoculum for collar rot of tobacco seedlings.

Ascospores of S. sclerotiorum, or plants with symptoms of diseases caused by $S$. sclerotiorum, have been reported from various times of the year. For example, Sclerotinia diseases have been reported from June to August in Canada $(3,6,11,16,17)$, July to September in Nebraska (11), New York (1), and North Dakota (8), April to July in California (9), November to March in Florida (10), and November to March in Israel (2). The presence of ascospores in tobacco greenhouses from February to April indicated that ascospores are continually produced and released in and around tobacco greenhouses during spring months in North Carolina. Preliminary sampling from other times of the year indicated that ascospores were not produced in the fall around tobacco greenhouses.

Highest numbers of ascospores were trapped in and around greenhouses that had severe collar rot problems in previous years, such as in greenhouse Wa-2 in Jones County. The high ascospore numbers trapped within $1 \mathrm{~m}$ of the greenhouse wall were probably the result of growers roguing and discarding seedlings with collar rot by throwing them out through open side vents of greenhouses. In addition, many growers discarded leaf clippings (leaf tissue that is removed three to seven times during seedling growth) that may contain infected leaf tissue just outside of the greenhouse. This leaf debris may become colonized by $S$. sclerotiorum and result in abundant sclerotia formation. Growers are now advised to discard this debris at least $100 \mathrm{~m}$ from the greenhouse or to bury it. Discarding the debris at least $100 \mathrm{~m}$ from the greenhouse should result in few ascospores entering the greenhouse the following year because of the steep dispersal gradient of ascospores (2). Although infected tobacco seedlings and leaf clippings are a source of sclerotia, it is possible that plants other than tobacco also are involved in sclerotia and ascospore production, since the fungus has a wide host range (4). Family gardens and numerous weeds are present close to these greenhouses and should be examined as a potential sources of inoculum.

Ascospore numbers were much higher outside than inside greenhouses, which indicated that the primary source of inoculum is outside. Ascospores apparently enter greenhouses when growers open side vents to prevent overheating and to reduce the relative humidity in the house. Different ventilation systems may help reduce movement of inoculum into houses.

At low inoculum levels, the distribution of ascospores followed a Poisson distribution, indicating that the source of inoculum was not close to the greenhouse. In fact, the source of the inoculum was not found for any of the greenhouses where a low level of inoculum was detected. As the number of ascospores trapped per dish increased, as in greenhouse Wa-2, the distribution inside the greenhouse became nonuniform, and abundant apothecia were found less than $1 \mathrm{~m}$ from the greenhouse wall. This source of inoculum provided a constant supply of ascospores throughout
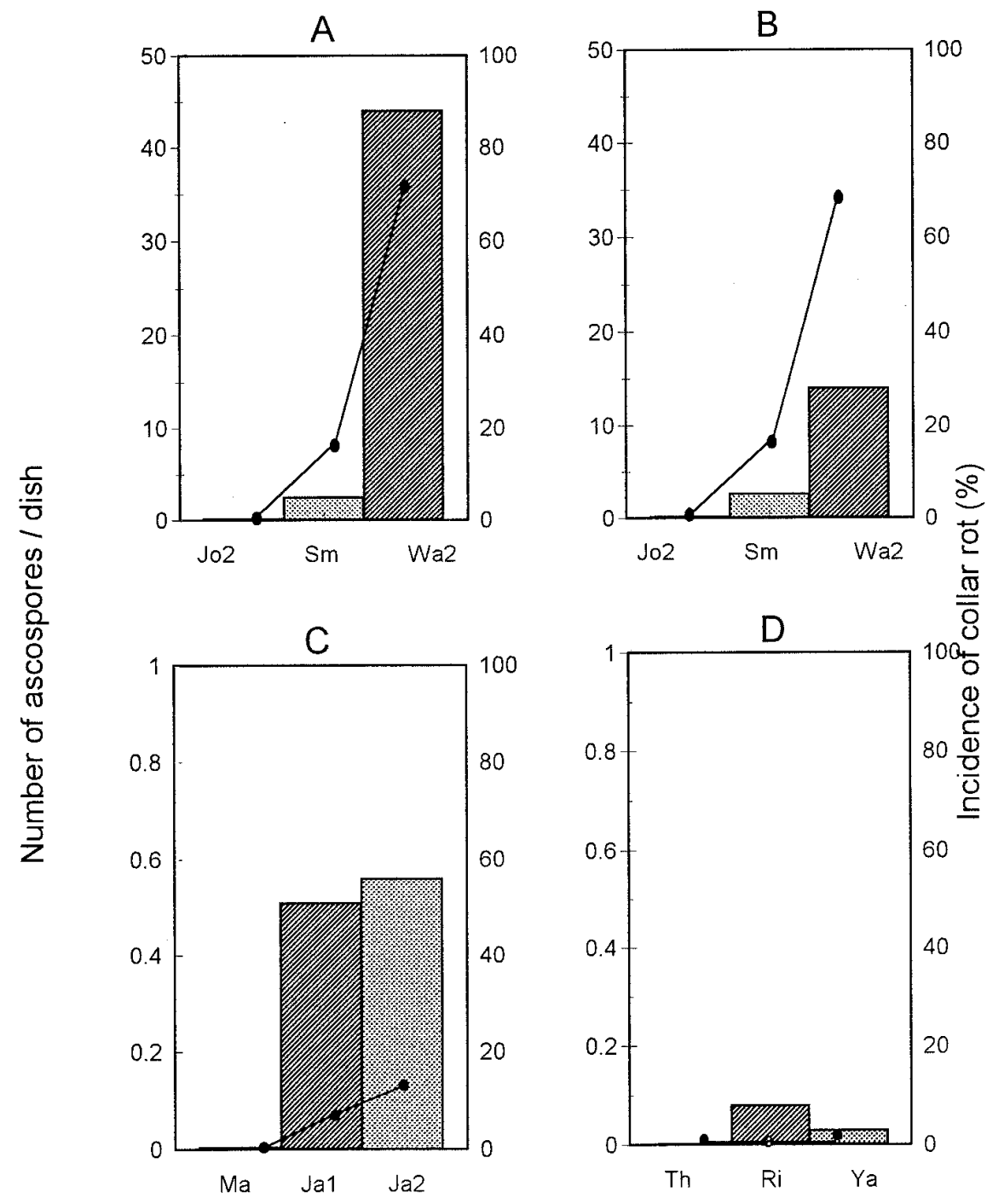

\section{Greenhouses}

Fig. 5. Incidence of collar rot in greenhouses in the counties studied. Bars indicate the average number of ascospores trapped per dish in each greenhouse; the solid line indicates the incidence of collar rot in greenhouses. (A) Jones and Lenoir county area 1995. (B) Jones and Lenoir county area 1996. (C) Martin County, 1996. (D) Caswell County, 1996. 
the transplant production period and resulted in high inoculum levels in the house. With intermediate inoculum levels, distribution of ascospores was random on some dates (f1, f2, f3, and f7) and nonrandom on others (f4, f5, and f6). Environmental effects on peak ascospore release from apothecia may have caused the occasional nonuniform distribution of ascospores inside the greenhouse.

Hourly trapping indicated that most ascospores were released between 7 A.M. and 2 P.M. These results agree with a previous study (2). The highest numbers of ascospores trapped were observed between 10 A.M. and noon outside the greenhouse, with about an hour delay to reach the highest numbers inside the greenhouse.

Collar rot was observed in all greenhouses with inoculum levels $>0.5$ colonies per dish; greatest disease incidence occurred in houses with the highest level of ascospores present. These observations indicate that ascospores are the primary inoculum for collar rot, and management practices that reduce ascospore numbers should reduce collar rot incidence. The use of fungicides to control this disease is possible, but there are currently no fungicides labeled for use in tobacco greenhouses in North Carolina.

\section{ACKNOWLEDGMENTS}

We thank Tom Melton, Allan Harper, Kent Yarborough, and Richard Williams for help in identi- fying greenhouses with collar rot, and Kenneth Jones, Leroy Whaley, Russel Smith, Brent Jackson, Leon Richmond, Tony Smith, and Edwing Yarborough for use of their greenhouse facilities to conduct tests. This work was made possible by a grant from the North Carolina Tobacco Research Commission.

\section{LITERATURE CITED}

1. Abawi, G. S., and Grogan, R. G. 1975. Source of primary inoculum and effects of temperature and moisture on infection of beans by Whetzelinia sclerotiorum. Phytopathology 65:300-309.

2. Ben-Yephet, Y., and Bitton, S. 1985. Use of a semi-selective medium to study the dispersal of ascospores of Sclerotinia sclerotiorum. Phytoparasitica 13:33-40.

3. Boland, G. J., and Hall, R. 1988. Relationship between the spatial pattern and number of apothecia of Sclerotinia sclerotiorum and stem rot of soybean. Plant Pathol. 37:329336.

4. Boland, G. J., and Hall, R. 1994. Index of plant hosts of Sclerotinia sclerotiorum. Can. J. Plant Pathol. 16:93-108.

5. Godoy, G., Steadman, J. R., Dickman, M. B., and Dam, R. 1990. Use of mutants to demonstrate the role of oxalic acid in pathogenicity of Sclerotinia sclerotiorum on Phaseolus vulgaris. Physiol. Mol. Plant Pathol. 37:179-191.

6. Gugel, R. K., and Morall, R. A. A. 1986. Inoculum-disease relationship in Sclerotinia stem rot of rapeseed in Saskatchewan. Can. J. Plant Pathol. 8:89-96.

7. Morral, R. A. A., and Dueck, J. 1982. Epidemiology of Sclerotinia stem rot of rapeseed in Saskatchewan. Can. J. Plant Pathol. 4:161168.
8. Nelson, B. D., Hertsgaard, D. M., and Holley, R. C. 1989. Disease progress of Sclerotinia wilt of sunflower at varying plant populations, inoculum densities, and environments. Phytopathology 79:1358-1363.

9. Patterson, C. L., and Grogan, R. G. 1985. Differences in epidemiology and control of lettuce drop caused by Sclerotinia minor and S. sclerotiorum. Plant Dis. 69:766-770.

10. Purdy, L. H. 1979. Sclerotinia sclerotiorum: History, disease and symptomatology, host range, geographic distribution, and impact. Phytopathology 69:875-880.

11. Schwartz, H. F., and Steadman, J. R. 1978. Factors affecting sclerotium population of and apothecium production by, Sclerotinia sclerotiorum. Phytopathology 68:383-388.

12. Sheskin, D. J. 1997. Handbook of Parametric and Nonparametric Statistical Procedures. CRC Press, Boca Raton, FL.

13. Snedecor, G. W., and Cochran, W. G. 1989. Statistical Methods. Iowa State University, Ames.

14. Steadman, J. R., Marcinkowsk, J., and Rutledge, S. 1994. A semi-selective medium for isolation of Sclerotinia sclerotiorum. Can. J. Plant Pathol. 16:68-70.

15. Steel, R. G. D., and Torrie, J. H. 1980. Principles and Procedures of Statistics: A Biometrical Approach. McGraw-Hill, New York.

16. Torres, J. A., and Moreno, R. 1991. Sclerotinia sclerotiorum: Epidemiological factors affecting infection on greenhouse aubergine crops. J. Phytopathol. 132:65-74.

17. Tu, J. C. 1989. Management of white mold of white beans in Ontario. Plant Dis. 73:281285.

18. Williams, J. R., and Stelfolk, D. 1979. Dispersal of ascospores of Sclerotinia sclerotiorum in relation to Sclerotinia stem rot of rapeseed. Plant Dis. Rep. 63:359-399. 